\title{
Atividades com Comunicação \& Educação Ano X - N. 3
}

Ruth Ribas Itacarambi

Doutora pela Faculdade de Educação da USP.

Educadora e pesquisadora do CAEM- Centro de Aperfeiçoamento do Ensino da Matemática do IME-USP.

Professora da FOC - Faculdade Osvaldo Cruz. Membro da Equipe SiteEducacional.

E-mail: ruthri@uol.com.br

A leitura do mundo precede a leitura da palavra

Paulo Freire

A questão da construção do conhecimento no ser humano está presente de forma explícita em três artigos desta edição. Embora apresentado em diferentes enfoques, torna-se necessário retomar o significado da visão construtivista sobre a aprendizagem, uma vez que nos propomos a mostrar atividades de ensino e aprendizagem.

Para Coll ${ }^{1}$, a concepção construtivista da aprendizagem escolar situa a atividade mental construtiva do aluno na base dos processos de desenvolvimento pessoal. Por aprendizagens significativas os educandos constroem, modificam, diversificam e coordenam os seus esquemas mentais, criando uma rede de significados que enriquecem seu conhecimento do mundo físico e social e potenciam seu crescimento pessoal.

O ser humano cria seu próprio conhecimento através da ação; por conseqüência, novos modos de equacionar a questão da construção do conhecimento se fazem necessários, derrubando-se a barreira da sala de aula convencional com novas práticas. O educador, nessa visão, é um mediador do processo de conhecimento do educando: pratica atividades que incentivem novas formas de "aprender a aprender"; modifica suas atitudes, aproximando-se dos jovens; propicia aos educandos ações em grupo, favorecendo a comunicação; e cria sempre novas situações de aprendizagem, que contemplam a interdisciplinaridade, visando tornar os educandos competentes para viverem como cidadãos no mundo contemporâneo.

Por outro lado, os seres humanos são contadores de histórias; então, compartilhar histórias é uma ferramenta poderosa para ajudar as pessoas a darem sentido a seus valores morais, a dividir seus valores com os outros e, assim,

1. COLL, Cesar. Psicologia e Currículo - São Paulo: Ática, 1987. p. 54-57. 
entender a si mesmo no seu processo de desenvolvimento. Histórias estão entre as nossas unidades mais básicas de comunicação.

As atividades com os artigos selecionados nesta edição têm como propósito discutir a construção do conhecimento na "sociedade da informação", onde a escola passa a ter novas funções: de fonte de informação passa a ter, também, o papel de proporcionar aos educandos a capacidade de refletir sobre as informações recebidas, examinando e julgando os valores éticos e morais consagrados na sociedade a partir de suas histórias e aprendendo a transformar informação em conhecimento. O desenvolvimento e a criação de novas sociabilidades são tratados nas atividades com a reflexão sobre a cibercultura, que coloca virtualmente a humanidade diante de si mesma.

Nesse contexto, vamos analisar o papel da narrativa em diferentes linguagens. A história em narrativas orais e em textos escritos é tratada no artigo de Sunwolf, Era uma vez, para a alma, que nos lembra que as histórias estão entre nossas unidades mais básicas de comunicação e de informação, e traz para a reflexão a questão de que "contar histórias é uma junção sensorial de imagens e idéias, um processo de recriar o passado nos termos do presente”. Já a linguagem imagética como imagem em movimento aparece no artigo de Gruzman e Anita Leandro, A pedagogia de Humberto Mauro: a natureza em Azulão e O João de Barro, por meio de seu método de representação da natureza na linguagem cinematográfica e o alcance pedagógico. $\mathrm{E}$ a imagem nos vídeos como instrumento facilitador da educação científica é o tema de estudo no artigo de Bortoliero, Bejarano e Hinkle, Das escavações à sociedade, que apresenta registro do conhecimento científico em vídeos, na perspectiva de entender e representar o entendimento do mundo por meio de símbolos.

\section{PRIMEIRA ATIVIDADE}

\section{Seres humanos contam histórias}

A atividade tem como objetivos discutir o ato de contar histórias como uma poderosa ferramenta de comunicação, que utiliza diferentes estruturas, desde o início da humanidade, e analisar o efeito delas sobre o ser humano quando as ouve. Esta questão é abordada no artigo de Sunwolf - Era uma vez, para a alma -, que trata das narrativas nas tradições espirituais. $\mathrm{O}$ autor concebe a espiritualidade no espaço amplo das religiões, como busca dinâmica e contínua dentro das pessoas pelo significado pessoal em relação com um poder divino superior. A sua posição é que as pessoas têm necessidade básica de espiritualidade para ajudá-las a dar sentido ao mundo, orientar suas escolhas sobre em que crer ou rejeitar, determinar o que valorizar a fim de guiar escolhas comportamentais.

O tema para a sala de aula deve se pautar por essa visão ampla da espiritualidade do ser humano. 
A atividade organiza-se mediante a utilização dos seguintes procedimentos:

1. Elaborar algumas perguntas iniciais para os educandos: Você gosta de histórias? Você lê histórias? Você aprecia ouvir histórias? Quais são suas histórias preferidas?

2. Com as informações, fazer a síntese dos depoimentos, dando uma atenção especial às histórias preferidas e sua estrutura.

3. Em seguida, ler no artigo o item "Estruturas de histórias", enfocando: a linguagem usada, os aspectos verbais e não-verbais, fábulas, parábolas, histórias familiares e histórias da mídia.

4. Convidar o educando a relatar uma história que leu e/ou ouviu, a qual lhe tenha provocado uma grande emoção.

5. Com os relatos, ler e comentar com os educandos o item "Efeitos de ouvir histórias", do mesmo artigo.

6. Em seguida, ler os modelos de cinco funções de histórias orais para contadores e ouvintes, apresentadas pelo autor, e pedir para os alunos elaborarem uma história e/ou pesquisarem histórias tendo como referencial os modelos apresentados; lembrar que, como o autor diz, tais modelos se misturam uns aos outros.

7. Criar um espaço para que histórias sejam contadas na escola e organizar com os educandos formas lúdicas de narrá-las. Seria interessante utilizar nesse espaço diferentes recursos, como representações gráficas, teatro, imagens veiculadas nas mídias etc.

\section{SEGUNDA ATIVIDADE}

\section{A imagem em movimento na construção do conhecimento}

A proposta desta atividade é a utilização da tecnologia do vídeo para a produção de materiais educativos, fazendo-se uma reflexão sobre o significado da linguagem cinematográfica na construção do conhecimento. Para fundamentar tal atividade, escolhemos o artigo de Gruzman e Anita Leandro, os quais, analisando o uso da imagem na escola, constatam que esta, por servir apenas como ilustração de um discurso precedente, "acaba tendo uma participação secundária na maioria dos processos educativos que a utilizam”. Para eles, como a educação não problematiza suficientemente a linguagem audiovisual, os vídeos educativos acabam reproduzindo a estética dominante da televisão e do cinema comercial, a qual não estimula o diálogo entre espectador e imagens, impedindo que o primeiro possa realmente aprender com o que observa.

$\mathrm{O}$ artigo de Bortoliero, Bejarano e Hinkle trata da relação entre Arte e Ciências, na perspectiva da produção de vídeos para a divulgação científica e como instrumento facilitador da educação científica dos jovens, desde que possa ser idealizada por eles em seu cotidiano.

Indicamos a seguir os procedimentos de ensino/aprendizado para o desenvolvimento da atividade. É importante que a escola possua pelo menos uma filmadora, fitas de vídeo, televisão e vídeo. 
1. Organizar na sala de aula a leitura e discussão do artigo de Gruzman e Leandro - A pedagogia de Humberto Mauro: a natureza em Azulão e o João de Barro -, a partir de dois enfoques: primeiro, localizar o momento histórico em que o filme foi feito e, segundo, a linguagem cinematográfica utilizada por Humberto Mauro na visão dos autores do artigo.

2. Relacionar as informações obtidas no artigo sobre o momento histórico com o conhecimento estudado em História sobre a primeira fase do governo Getúlio Vargas e a criação do Instituto Nacional de Cinema Educativo (INCE).

3. Registrar as diretrizes apresentadas no artigo, como as de Roquete Pinto, para a elaboração dos filmes e comparar com as transgressões de Humberto Mauro.

4. Programar a apresentação de filmes que tratem da natureza e possibilitem ao espectador aprender a partir do que vê, o que é possível consultando videolocadoras e cinematecas.

5. Discutir o filme, após a sessão, e comparar com as concepções sobre a linguagem cinematográfica apresentada no artigo, nos itens: "O geral e o particular" e "A relação com o tempo".

6. Analisar as possíveis contribuições dos filmes, no cinema e nos vídeos, em processos de construção do conhecimento sobre a natureza e a ciência em geral.

7. Organizar a produção de vídeos em grupos, como documentário sobre a natureza e/ou outro conhecimento científico de interesse do grupo, numa proposta de investigação. O artigo Das escavações à sociedade, de Hinkle, Bortoliero e Bejarano, traz uma seqüência de atividades no item "A trajetória e o contexto da investigação", que podem ser úteis tanto para a definição do tema quanto para a elaboração do roteiro das filmagens.

8. Proporcionar sessões de filmes na sala de aula e discutir a estética, tendo como referencial as considerações dos itens 4 e 5 .

9. Após essas sessões, programar uma apresentação para a comunidade escolar e, na exibição de cada vídeo, pedir para que os educandos presentes registrem as imagens mais significativas e o que aprenderam com elas.

10. Resgatar na sala de aula as considerações da comunidade escolar sobre os vídeos apresentados e os objetivos do grupo na elaboração do vídeo.

\section{TERCEIRA ATIVIDADE}

\section{A humanidade virtualmente diante de si mesma}

O intuito da atividade é observar alguns assuntos, como: a utilização das tecnologias de informação e comunicação nas sociedades modernas; o tema da inclusão digital nas atuais relações sociais; a questão das redes nas escolas e sociedades, onde diferentes pontos estão conectados sem uma hierarquia, e a eliminação de um dos pontos não interrompe o fluxo de informação no resto da rede (assim, temos na escola hoje algumas redes: rede do saber, rede 
do conhecimento, escolas em rede etc.); e a constatação de que a tecnologia não é neutra.

O artigo que tomamos como referência é o de Josgrilberg, Tecnologia $e$ sociedade: entre os paradoxos e os sentidos possíveis. Segundo o autor, o paradigma informacional marca a forma de compreensão da realidade, ou seja, uma sobredeterminação da lógica informacional em forma binária dos zeros e uns; assim como a metáfora da rede que aparentemente organiza o imaginário da globalização em diversas facetas: rede de conhecimento, rede tecnológica, rede de solidariedade etc.

A atividade de ensino e aprendizagem está organizada nos seguintes procedimentos:

1. Sintetizar o artigo para os alunos, apresentando as seguintes questões: O que é inclusão digital? Como funciona uma rede de comunicação? Que mudanças sociais ocorreram com o uso da informática?

2. Propor aos alunos uma conversa informal com seus avós e pais ou com idosos da comunidade para saber como eram as relações sociais na sua juventude e o que mudou com a presença das novas tecnologias.

3. Comparar as informações obtidas com as considerações do grupo/classe no item 1.

4. Pesquisar redes de comunicação de jovens na internet e registrar alguns dos temas que são abordados por eles.

5. Retomar o estudo sobre a revolução industrial abordado nas aulas de História e comparar com as considerações do autor sobre a segunda revolução técnico-industrial.

6. Discutir com os alunos sobre se a tecnologia não é neutra e como podemos utilizá-la de forma criativa e em benefício da sociedade. 
Resumo: A autora propõe a atividade com o objetivo de discutir o ato de contar histórias como uma poderosa ferramenta de comunicação, que utiliza diferentes estruturas, desde o início da humanidade, e o efeito delas sobre o ser humano quando as ouve. Essa questão é abordada no artigo de Sunwolf - Era uma vez, para a alma -, que trata das narrativas nas tradições espirituais. A segunda atividade tem como tema gerador a imagem em movimento na construção do conhecimento. Para fundamentá-la, foram escolhidos os artigos Pedagogia de Humberto Mauro: a natureza em Azulão e o João de Barro e Das escavações à sociedade: a divulgação científica sob a ótica das crianças de Peirópolis, que trata da relação entre Arte e Ciências, na perspectiva da produção de vídeos para a divulgação científica e como instrumento facilitador da educação científica dos jovens, desde que possa ser idealizada por eles em seu cotidiano. Na terceira atividade, o tema gerador é a humanidade da era virtual diante de si mesma, em que é proposta uma discussão sobre a utilização das tecnologias de informação e comunicação nas sociedades atuais. Abordam-se questões como a inclusão digital nas atuais relações sociais e as redes nas escolas e sociedades. $O$ artigo de referência é Tecnologia e sociedade: entre os paradoxos e os sentidos possíveis, de Fabio B. Josgrilberg.

Palavras-chave: sociedade da informação, narrativas orais, ciência, divulgação científica, tecnologia de informação e comunicação.
Abstract: The author proposes activities with the objective of discussing the storytelling as a powerful communication tool, with the use of different structures, since the beginning of the human kind, and their effect in the human being. This issue is approached in the article of Sunwolf Era uma vez, para a alma that deals with narrative in spiritual traditions. The second activity has as generating theme the image and movement in knowledge building. The articles chosen are: Pedagogy of Humberto Mauro and From digs to society, that deals with the relationship between Art and Science in the perspective of video production for scientific divulgence and as tool for facilitating Science education since it can be idealized by youth in their daily life. The third activity generating theme is the human kind virtually in front of itself, where the author proposes a discussion on the use of information and communication technologies in present societies. It approaches the issue of digital inclusion in current social relations and the issue of nets in schools and societies. The reference article is Technology and society.

Keywords: information society, oral narratives, science, scientific divulgence, information and technology. 